\title{
Increased Serum Levels of C21 Steroids in Female Patients With Multiple Sclerosis
}

\author{
R. KANCEVA ${ }^{1}$, L. STÁRKA ${ }^{1}$, L. KANCHEVA ${ }^{1}$, M. HILL ${ }^{1}$, M. VELIKOVÁ ${ }^{1}$, \\ E. HAVRDOVÁ ${ }^{2}$
}

${ }^{1}$ Institute of Endocrinology, Prague, Czech Republic, ${ }^{2}$ Demyelination Disease Center (MS Center), Department of Neurology, First Faculty of Medicine and General Teaching Hospital, Charles University, Prague, Czech Republic

Received July 20, 2015

Accepted August 3, 2015

\section{Summary}

Multiple sclerosis (MS) is one of the most common neurological diseases. This neurodegenerative autoimmune disease manifests as inflammatory and demyelinating impairment of the central nervous system (CNS). Although some studies demonstrated associations between altered steroidogenesis and pathophysiology of MS as well as the importance of steroids in the pathophysiology of MS, the knowledge concerning the steroid metabolome in female patients is limited. Hence, 51 steroids and steroid polar conjugates were measured in the serum of 12 women with MS, untreated with steroids and 6 agecorresponding female controls with the use of gas chromatography - mass spectrometry (GC-MS). The data were processed using age adjusted ANCOVA, receiver operating characteristics (ROC) analysis and orthogonal projections to latent structures (OPLS). Our data show higher levels of circulating C21 steroids including steroid modulators of ionotropic type $A$ y-aminobutyric acid (GABA A) receptors and glutamate receptors. Furthermore, the levels of GABAergic androsterone and 5 -androsten-3 $3,7 a, 17 \beta$-triol were also higher in the female MS patients. In conclusion, the data demonstrate higher levels of circulating C21 steroids and their polar conjugates and some bioactive C19 steroids in women with MS, which may influence neuronal activity and affect the balance between neuroprotection and excitotoxicity.

\section{Key words}

Multiple sclerosis • Women • Neurosteroids • GC-MS • Multivariate regression

\section{Corresponding author}

R. Kanceva, Institute of Endocrinology, Národní třída 8, 11694 Prague, Czech Republic. E-mail: rkanceva@endo.cz

\section{Introduction}

Steroid hormones known as neurosteroids are synthesized in the human central nervous system (CNS) (Leitner 2010). Neurosteroids have been studied in different addicting disorders (Duskova et al. 2012) and also in neurological diseases. Multiple sclerosis (MS) is one of the most common neurological diseases. This neurodegenerative autoimmune disease manifests as inflammatory and demyelinating impairment of the CNS. Whereas the present pharmacological treatment of the disease is limited to the application of immunomodulatory and antiinflammatory substances, which are not primarily targeted to the causation of the disease, there is a need for drugs promoting the neuronal viability (El-Etr et al. 2011). Beside others, some endogenous steroids like the sex hormones and GABAergic steroids as well as their artificial derivatives may be promising as targeted drugs (Melcangi et al. 2014). Even if some studies demonstrated associations between altered steroidogenesis and pathophysiology of MS as well as the importance of steroids in the pathophysiology of the disease, the knowledge concerning the steroid metabolome in human is limited, particularly in female patients (Bove and Chitnis 2014, Caruso et al. 2014, El-Etr et al. 2005, 2011, Noorbakhsh et al. 2011, Spence and Voskuhl 2012, Tomassini and Pozzilli 2009). Taking into account that a substantial part 
of steroid metabolome in the CNS may reflect the peripheral steroidogenesis (Kancheva et al. 2011), we attempted to systematically investigate these relationships between the circulating steroids and MS using a multicomponent steroid profiling by gas chromatography - mass spectrometry (GC-MS). In addition, taking advantage of multicollinearity between circulating steroids, we tried to set up a multivariate prediction model differentiating female MS patients from the corresponding controls.

\section{Materials and Methods}

\section{Subjects}

The study was approved by the Ethics Committee of the Institute of Endocrinology. All women signed informed consent form before entering the study. Participants were 12 women with MS not treated with steroids and 6 age-corresponding female controls who were in the follicular phase of the menstrual cycle. They were 36 years of age $(26,47)$ (shown as median quartiles).

\section{Chemicals}

Steroids were purchased from Steraloids (Newport, RI, USA), Sylon B from Supelco (Bellefonte, PA, USA), methoxylamine hydrochloride from Sigma (St. Louis, MO, USA) and solvents from Merck (Darmstadt, Germany).

\section{Analytical methods}

The circulating levels of steroids and their polar conjugates were measured using the previously described GC-MS method (Hill et al. 2010).

\section{Instruments}

Measurements of steroid levels were done on GCMS-QP2010 Plus system by Shimadzu (Kyoto, Japan) consisting of a gas chromatograph equipped with automatic flow control, an AOC-20s autosampler, and a single quadrupole detector with an adjustable electron voltage of 10-195 V. A capillary column with a medium polarity RESTEK Rxi ${ }^{\mathrm{TM}}-50$ (diameter $0.25 \mathrm{~mm}$, length $15 \mathrm{~m}$, film thickness $0.1 \mu \mathrm{m}$ ) was used for analyses. Electron impact ionization with electron voltage fixed at $70 \mathrm{~V}$ and emission current set to $160 \mu \mathrm{A}$ was used. The temperatures of the injection port, ion source and interface were maintained at $220{ }^{\circ} \mathrm{C}, 300^{\circ} \mathrm{C}$, and $310^{\circ} \mathrm{C}$, respectively. Analyses were carried out in the splitless mode with a constant linear velocity of the carrier gas (He), which was maintained at $60 \mathrm{~cm} / \mathrm{s}$. The septum purge flow was set at $3 \mathrm{ml} / \mathrm{min}$. The samples were injected using the high pressure mode $(200 \mathrm{kPa})$, which was maintained for $1 \mathrm{~min}$. The detector voltage was set to $1.2 \mathrm{kV}$.

\section{Statistical analysis}

To correctly explain the relationships between steroids and presence of MS in women, we used three independent statistical approaches. The first compares the steroid levels in MS and age- and gender-corresponding controls. In spite of comparable age of both groups, we used age-adjusted ANCOVA for this purpose to separate the variability in dependent variable shared with age from that explained by status of the subjects (MS vs. controls). Respecting the skewed distribution and non-constant variance in most dependent variables, these were transformed by power transformations to data symmetry and homoscedasticity prior further processing (Meloun et al. 2000). The homogeneity and distribution of the transformed data was checked by residual analysis as described elsewhere (Meloun et al. 2002, 2004). Statistical software Statgraphics Centurion, version XV from Statpoint Inc. (Herndon, Virginia, USA) was used for ANCOVA.

The second method used for data evaluation was the receiver operating characteristics (ROC) analysis. This method enables the finding of optimum cut-off values from individual dependent variables to differentiate between patients and controls. The positivity of the pathology may be detected at values higher or below this cut-off value. The effectiveness of individual variables for prediction of MS was assessed using area under curve (AUC) in the plot of sensitivity vs. 1 -specificity and the significance of AUC in this plot was evaluated by one sided test (hypothesis that the AUC is significantly greater than 0.5 ). Statistical software NCSS 2007 from Number Cruncher Statistical Systems (Kaysville, Utah, USA) was used for the ROC analysis.

The third and most efficient method was simultaneous evaluation of relationships between steroids and the presence of MS by multivariate regression with a reduction of dimensionality known as orthogonal projections to latent structure (OPLS) (Madsen et al. 2010, Trygg and Wold 2002, Trygg et al. 2007), which is capable to cope with a problem of severe multicollinearity (high intercorrelations) in the matrix of predictors, whilst the ordinary multiple regression fails to 
correctly evaluate such data. The multicollinearity in OPLS is favorable as it enhances a predictivity of the model.

In our model, the logarithm of the ratio of probability of pathology presence to probability of pathology absence (logarithm of likelihood ratio, LLR), was chosen as the single dependent variable, while the steroid levels represented the predictors. The variability in predictors was separated into two independent components. The first one contained the variability predictors, which was shared with probability of the pathology (the predictive component) while the orthogonal components explained the variability shared within the highly intercorrelated predictors.

The OPLS identified the best predictors as well as the best combination of predictors to estimate the probability of the pathology presence. After standardization of the variables, the OPLS model can be expressed as follows:

$$
\begin{aligned}
& \mathbf{X}=\mathbf{T}_{p} \mathbf{P}_{p}{ }^{t}+\mathbf{T}_{0} \mathbf{P}_{0}{ }^{t}+\mathbf{E} \\
& \mathbf{Y}=\mathbf{T}_{p} \mathbf{P}_{p}{ }^{t}+\mathbf{F}
\end{aligned}
$$

where $\mathbf{X}$ is the matrix with $l$ predictors and $i$ subjects, $\mathbf{Y}$ is the vector of dependent variable and $i$ subjects. $\mathbf{T}_{\mathrm{p}}$ represents the vector of component scores from the single predictive component and $i$ subjects extracted from $\mathbf{Y}, \mathbf{T}_{\mathrm{o}}$ is the vector of component scores from the single orthogonal component and $i$ subjects extracted from $\mathbf{X}$, $\mathbf{P}_{\mathrm{p}}$ represents the vector of component loadings for the predictive component extracted from $\mathbf{Y}$. $\mathbf{P}_{\mathrm{o}}$ represents the vector of component loadings for the orthogonal component extracted from $\mathbf{X}$ and $l$ independent variables, while $\mathbf{E}$ and $\mathbf{F}$ are the error terms.

The relevant predictors have been chosen using variable importance ("VIP") statistics. The statistical software SIMCA-P v.12.0 from Umetrics AB (Umeå, Sweden), which was used for OPLS analysis, enabled to find the number of relevant components, the detection of multivariate non-homogeneities and testing the multivariate normal distribution and homoscedasticity (constant variance).

The algorithm for obtaining the predictions is as follows: a) transformation of the original data to obtain the values with symmetric distribution and constant variance, b) checking the data homogeneity in predictors using Hotelling's statistics and eventual elimination of non-homogeneities, c) testing the relevance of predictors using the Variable importance statistics and elimination of irrelevant predictors, d) calculation of component loadings for individual variables to evaluate their correlations with predictive component, e) calculation of regression coefficients for the multiple regression model to evaluate mutual independence of predictors after comparison with the corresponding component loadings from the OPLS model, f) calculation of predicted values of logarithm of the ratio of probability of pathology presence to probability of pathology absence (LLR), g) calculation of probability of the pathology presence for individual subjects, h) calculation of sensitivity and specificity of the prediction.

\section{Results}

\section{Age-adjusted ANCOVA}

The differences between steroid levels of female patients with MS and age- and gender-corresponding controls are shown in Table 1. These data indicate higher levels of most C21 steroids, androstenedione and estriol in MS patients when compared to controls.

\section{ROC analysis}

Table 2 shows a similar trend as Table 1. The levels of various C21 steroids including most $5 \alpha / \beta$ reduced $\mathrm{C} 21$ steroids exhibit significant areas under curve in receiver operating characteristics (ROC) with higher levels of these substances in MS patients. In addition, estriol and some 5 $\alpha$-reduced $\mathrm{C} 19$ steroids such as androsterone and epiandrosterone are also higher in the patients. Although the levels of progesterone do not significantly differ between the female MS patients and controls, its $5 \alpha / \beta$-reduced catabolites as well as $16 \alpha$-hydroxy and 20 $\alpha$-dihydro-metabolites are significantly elevated in the patients.

\section{OPLS model}

Table 3 also demonstrates that most C21 steroids, two conjugated $5 \alpha / \beta$-reduced androstanes and estriol positively correlate with the presence of MS in women. From the C21 steroids, the correlation of progesterone with MS does not reach significance but its $5 \alpha / \beta$-reduced catabolites as well as $16 \alpha$-hydroxy and $20 \alpha$-dihydro-metabolites are significantly elevated in the patients. The predictivity of the OPLS model was absolute (sensitivity $=1.000(0.758,1.000)$; specificity $=$ $1.000(0.566,1.000)$ - shown as estimates with $95 \%$ confidence limits). 
Table 1. Levels of circulating steroids (nM) in female patients with multiple sclerosis (MS) and in age- and gender-corresponding controls (C) as evaluated by age-adjusted ANCOVA (significant differences are in bold).

\begin{tabular}{|c|c|c|c|c|}
\hline \multirow{2}{*}{ Variable } & \multicolumn{2}{|c|}{ Mean ( $95 \%$ confidence limits) } & \multicolumn{2}{|c|}{ ANCOVA, MS } \\
\hline & C & MS & $F$ & $p$ \\
\hline Pregnenolone & $0.673(0.49,0.903)$ & $1.47(1.22,1.78)$ & 11.4 & 0.004 \\
\hline Pregnenolone sulfate & $41.8(33.6,51.8)$ & $102(85.7,121)$ & 23.2 & $<0.001$ \\
\hline 16 $\alpha$-Hydroxypregnenolone & $0.2(0.127,0.293)$ & $0.36(0.283,0.451)$ & 3.8 & 0.07 \\
\hline 17-Hydroxypregnenolone & $0.733(0.345,1.42)$ & $2.04(1.29,3.17)$ & 3.6 & 0.078 \\
\hline 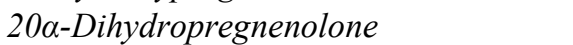 & $2.55(1.9,3.39)$ & $3.26(2.68,3.95)$ & 1.1 & 0.312 \\
\hline 20a-Dihydropregnenolone sulfate & $355(299,424)$ & $685(581,815)$ & 16.5 & 0.002 \\
\hline Dehydroepiandrosterone (DHEA) & $10.9(7.38,14.2)$ & $15.3(13,17.5)$ & 2.6 & 0.129 \\
\hline DHEA sulfate (DHEAS) & $1740(1160,2540)$ & $3130(2390,4060)$ & 3.5 & 0.084 \\
\hline $7 \alpha-H y d r o x y-D H E A$ & $0.612(0.457,0.784)$ & $0.874(0.757,0.998)$ & 3.6 & 0.079 \\
\hline 7-охо-DHEA & $0.297(0.215,0.416)$ & $0.34(0.27,0.431)$ & 0.2 & 0.628 \\
\hline 7 $\beta$-Hydroxy-DHEA & $0.592(0.452,0.751)$ & $0.626(0.523,0.738)$ & 0.1 & 0.791 \\
\hline 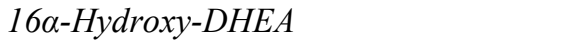 & $0.157(0.11,0.218)$ & $0.207(0.165,0.259)$ & 1.1 & 0.317 \\
\hline 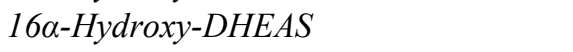 & $9.91(7.08,14.5)$ & $11.9(9.12,15.9)$ & 0.3 & 0.568 \\
\hline Androstenediol & $1.72(1.14,2.53)$ & $1.72(1.29,2.25)$ & 0 & 0.995 \\
\hline Androstenediol sulfate & $562(324,921)$ & $554(374,797)$ & 0 & 0.974 \\
\hline 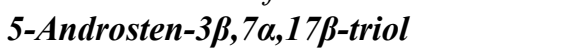 & $0.0724(0.0604,0.0852)$ & $0.117(0.106,0.128)$ & 15.9 & 0.002 \\
\hline 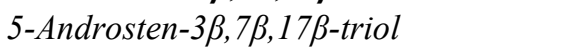 & $0.0783(0.058,0.107)$ & $0.0827(0.0668,0.103)$ & 0.1 & 0.831 \\
\hline Progesterone & $0.419(0.281,0.641)$ & $0.741(0.541,1.05)$ & 2.6 & 0.13 \\
\hline 16a-Hydroxyprogesterone & $0.472(0.314,0.735)$ & $0.655(0.483,0.917)$ & 0.8 & 0.375 \\
\hline 20a-Dihydroprogesterone & $0.319(0.263,0.392)$ & $0.626(0.521,0.771)$ & 12.9 & 0.003 \\
\hline $5 \alpha$-Dihydroprogesterone & $0.122(0.0893,0.17)$ & $0.166(0.132,0.213)$ & 1.3 & 0.27 \\
\hline Androstenedione & $1.59(1.2,2.04)$ & $2.74(2.4,3.12)$ & 8.9 & 0.01 \\
\hline Testosterone & $0.803(0.649,1.03)$ & $0.927(0.785,1.12)$ & 0.5 & 0.479 \\
\hline $5 \alpha$-Dihydrotestosterone & $0.552(0.372,0.85)$ & $0.487(0.37,0.649)$ & 0.1 & 0.71 \\
\hline Epitestosterone & $0.386(0.25,0.556)$ & $0.447(0.34,0.571)$ & 0.2 & 0.647 \\
\hline Estrone & $0.306(0.227,0.424)$ & $0.213(0.173,0.264)$ & 2.2 & 0.164 \\
\hline Estrone sulfate & $1.38(0.718,2.88)$ & $1.27(0.789,2.11)$ & 0 & 0.881 \\
\hline Estradiol & $0.158(0.0759,0.333)$ & $0.175(0.105,0.294)$ & 0 & 0.871 \\
\hline Estriol & $0.0386(0.0328,0.0463)$ & $0.06(0.0513,0.072)$ & 7.3 & 0.016 \\
\hline Allopregnanolone & $0.176(0.134,0.228)$ & $0.444(0.371,0.529)$ & 20.2 & $<0.001$ \\
\hline Allopregnanolone sulfate & $3.74(2.77,5.11)$ & $7.68(5.96,10.2)$ & 6.9 & 0.02 \\
\hline Isopregnanolone & $0.104(0.0849,0.127)$ & $0.191(0.164,0.224)$ & 12.7 & 0.003 \\
\hline Isopregnanolone sulfate & $4.1(3.39,4.94)$ & $9.21(7.9,10.8)$ & 25.2 & $<0.001$ \\
\hline Pregnanolone & $0.0937(0.0745,0.12)$ & $0.141(0.117,0.176)$ & 3.7 & 0.073 \\
\hline Conjugated pregnanolone & $8.75(6.91,11.2)$ & $15.9(12.9,20.2)$ & 7.2 & 0.018 \\
\hline Epipregnanolone & $0.0261(0.0187,0.0372)$ & $0.0485(0.0371,0.0655)$ & 4.2 & 0.058 \\
\hline Conjugated epipregnanolone & $0.671(0.428,0.994)$ & $1.38(1.06,1.77)$ & 5.2 & 0.039 \\
\hline Conjugated $5 \alpha$-pregnane- $3 \beta, 20 \alpha-$-diol & $119(78.7,179)$ & $264(194,368)$ & 5.3 & 0.037 \\
\hline Conjugated $5 \beta$-pregnane-3$\alpha, 20 \alpha$-diol & $14.2(11.4,18.3)$ & $23(18.6,29.4)$ & 4.7 & 0.049 \\
\hline Androsterone & $0.341(0.275,0.42)$ & $0.424(0.366,0.488)$ & 1.6 & 0.226 \\
\hline Androsterone sulfate & $658(362,1000)$ & $699(475,949)$ & 0 & 0.88 \\
\hline Epiandrosterone & $0.517(0.367,0.675)$ & $0.749(0.636,0.866)$ & 3.1 & 0.097 \\
\hline Epiandrosterone sulfate & $227(126,362)$ & $328(233,443)$ & 0.9 & 0.371 \\
\hline Etiocholanolone & $0.188(0.143,0.247)$ & $0.207(0.171,0.252)$ & 0.2 & 0.667 \\
\hline Conjugated etiocholanolone & $46.4(27.9,72.2)$ & $46.7(32.6,64.6)$ & 0 & 0.988 \\
\hline Epietiocholanolone & $0.0309(0.0235,0.0421)$ & $0.0305(0.0252,0.0377)$ & 0 & 0.964 \\
\hline Conjugated epietiocholanolone & $16.4(7.81,30.1)$ & $23.7(14.9,35.7)$ & 0.5 & 0.494 \\
\hline $5 \alpha$-Androstane- $3 \alpha, 17 \beta$-diol & $0.0497(0.0329,0.0723)$ & $0.0856(0.0679,0.107)$ & 3.5 & 0.083 \\
\hline Conjugated $5 \alpha$-androstane- $3 \alpha, 17 \beta$-diol & $31.8(20.3,45.3)$ & $29(20.8,38.2)$ & 0.1 & 0.785 \\
\hline Conjugated $5 \alpha$-androstane- $3 \beta, 17 \beta$-diol & $38.8(19.1,67.8)$ & $45.4(28.7,67.5)$ & 0.1 & 0.758 \\
\hline Conjugated $5 \beta$-androstane- $3 \alpha, 17 \beta$-diol & $6.74(4.33,9.27)$ & $6.79(5.03,8.62)$ & 0 & 0.979 \\
\hline
\end{tabular}


Table 2. ROC analysis of steroid levels for the differentiation of female patients with multiple sclerosis (MS) from age- and gendercorresponding controls (C).

\begin{tabular}{|c|c|c|c|c|c|c|}
\hline Steroid & $\begin{array}{c}\text { Cut-off value } \\
\text { (patient) }\end{array}$ & Sensitivity & Specificity & $\begin{array}{l}\text { Youden's } \\
\text { statistics }\end{array}$ & AUC & $\begin{array}{c}\text { p-value } \\
\text { (one-sided) }\end{array}$ \\
\hline Pregnenolone & $>1.03$ & 83.3 & 100 & 0.833 & 0.903 & $<0.001$ \\
\hline Pregnenolone sulfate & $>56.2$ & 90.9 & 100 & 0.909 & 0.909 & $<0.001$ \\
\hline 16a-Hydroxypregnenolone & $>0.23$ & 83.3 & 66.7 & 0.5 & 0.75 & 0.029 \\
\hline 17-Hydroxypregnenolone & $>1.32$ & 72.7 & 83.3 & 0.561 & 0.773 & 0.011 \\
\hline 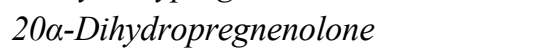 & $>2.65$ & 83.3 & 66.7 & 0.5 & 0.736 & 0.029 \\
\hline 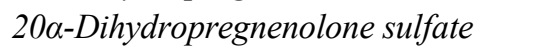 & $>480$ & 81.8 & 100 & 0.818 & 0.879 & $<0.001$ \\
\hline 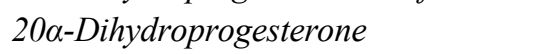 & $>0.34$ & 100 & 83.3 & 0.833 & 0.958 & $<0.001$ \\
\hline Estriol & $>0.05$ & 66.7 & 100 & 0.667 & 0.861 & $<0.001$ \\
\hline Allopregnanolone & $>0.24$ & 83.3 & 100 & 0.833 & 0.833 & 0.002 \\
\hline Allopregnanolone sulfate & $>6.57$ & 63.6 & 100 & 0.636 & 0.864 & $<0.001$ \\
\hline Isopregnanolone & $>0.15$ & 75 & 100 & 0.75 & 0.917 & $<0.001$ \\
\hline Isopregnanolone sulfate & $>4.75$ & 90.9 & 100 & 0.909 & 0.939 & $<0.001$ \\
\hline Pregnanolone & $>0.08$ & 100 & 50 & 0.5 & 0.819 & 0.002 \\
\hline Conjugated pregnanolone & $>11.8$ & 72.7 & 100 & 0.727 & 0.848 & $<0.001$ \\
\hline Epipregnanolone & $>0.03$ & 75 & 66.7 & 0.417 & 0.736 & 0.035 \\
\hline Conjugated epipregnanolone & $>0.8$ & 90.9 & 66.7 & 0.576 & 0.803 & 0.008 \\
\hline Conjugated $5 \alpha$-pregnane- $3 \beta, 20 \alpha$-diol & $>254$ & 72.7 & 100 & 0.727 & 0.788 & 0.008 \\
\hline Conjugated $5 \beta$-pregnane- $3 \alpha, 20 \alpha$-diol & $>21.3$ & 63.6 & 100 & 0.636 & 0.818 & 0.002 \\
\hline Androsterone & $>0.37$ & 75 & 83.3 & 0.583 & 0.792 & 0.006 \\
\hline Epiandrosterone & $>0.64$ & 75 & 83.3 & 0.583 & 0.764 & 0.024 \\
\hline
\end{tabular}

Table 3. Relationships between $\log$ (probability of MS presence/probability of MS absence) (matrix $\mathbf{Y}$ ) and circulating steroids (matrix $\mathbf{X}$ ) as evaluated by multiple regression with reduction of dimensionality (method of orthogonal predictions to latent structure, OPLS).

\begin{tabular}{|c|c|c|c|c|c|}
\hline & \multirow{2}{*}{ Predictors } & \multicolumn{4}{|c|}{ OPLS model } \\
\hline & & Component loading $^{a}$ & t-statistic ${ }^{b}$ & $\mathbf{R}^{\mathbf{c}}$ & \\
\hline \multirow{16}{*}{ matrix $\mathbf{X}$} & Pregnenolone & 0.255 & 2.89 & 0.711 & $*$ \\
\hline & Pregnenolone sulfate & 0.267 & 9.56 & 0.768 & $* *$ \\
\hline & 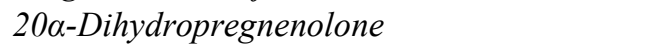 & 0.241 & 7.22 & 0.672 & $* *$ \\
\hline & $20 \alpha$-Dihydropregnenolone sulfate & 0.248 & 7.47 & 0.713 & $* *$ \\
\hline & 16a-Hydroxypregnenolone & 0.197 & 1.78 & 0.550 & \\
\hline & $20 \alpha$-Dihydroprogesterone & 0.287 & 7.11 & 0.801 & $* *$ \\
\hline & Estriol & 0.183 & 2.33 & 0.511 & $*$ \\
\hline & Allopregnanolone & 0.243 & 9.95 & 0.679 & $* *$ \\
\hline & Allopregnanolone sulfate & 0.297 & 5.62 & 0.857 & $* *$ \\
\hline & Isopregnanolone & 0.250 & 3.16 & 0.699 & $* *$ \\
\hline & Isopregnanolone sulfate & 0.331 & 12.80 & 0.953 & $* *$ \\
\hline & Pregnanolone & 0.218 & 4.61 & 0.607 & $* *$ \\
\hline & Conjugated pregnanolone & 0.246 & 2.78 & 0.710 & $*$ \\
\hline & Epipregnanolone & 0.227 & 4.00 & 0.633 & $* *$ \\
\hline & Conjugated $5 \beta$-pregnane- $3 \alpha, 20 \alpha$-diol & 0.230 & 2.17 & 0.664 & $*$ \\
\hline & Conjugated $5 \alpha$-pregnane- $3 \beta, 20 \alpha$-diol & 0.288 & 16.65 & 0.830 & $* *$ \\
\hline matrix $\mathbf{Y}$ & $\begin{array}{l}\log \text { (Probability of presencelabsence of the } \\
\text { disease) (logarithm of likelihood ratio, LLR) }\end{array}$ & 1.000 & 15.37 & 0.794 & $* *$ \\
\hline
\end{tabular}

$$
\text { Explained variability } 63 \%(57.9 \%)
$$

$a$ - component loadings for the predictive components expressed as regression coefficients; $b-t$-statistic is the ratio of the regression coefficient to its standard error; $\mathrm{c}$ - component loadings for the predictive components expressed as correlation coefficients of predictors with predictive components; ${ }^{*} p<0.05,{ }^{*} p<0.01$; value in parentheses represents explained variability after a cross-validation. 


\section{Discussion}

This is the first study systematically investigating alterations in circulating steroids of female patients with multiple sclerosis. Three independent statistical approaches giving the same conclusions were used for the evaluation of experimental data. Our results are partly in accordance with the data of Caruso et al. (2014) reporting significantly increased circulating levels of pregnenolone, progesterone and isopregnanolone in male patients with MS. However, differences for progesterone levels in our data do not reach significance despite $77 \%$ increase of progesterone in the patients. Furthermore, the levels of both allopregnanolone and allopregnanolone sulfate are even significantly elevated like the levels of their 3 $\beta$-hydroxy-counterparts isopregnanolone and isopregnanolone sulfate (Table 1). In accordance with the data of Caruso et al. (2014), circulating androgens and estrogens do not show significant differences between controls and patients in our data except higher levels of estriol and two $5 \alpha / \beta$-reduced androstanes in the patients. The discrepancies in allopregnanolone might be ascribed to gender differences as the female allopregnanolone is produced in both ovaries and adrenals, while the male circulating allopregnanolone is of adrenal origin (Havlikova et al. 2006, Kancheva et al. 2007).

Concerning the pathophysiological importance of systematically increased levels of circulating C21 steroids in women with MS, allopregnanolone and progesterone are known to attenuate the neuroinflammation in MS patients by numerous mechanisms (Melcangi et al. 2014, Noorbakhsh et al. 2014). Pregnenolone sulfate is known as a subtypespecific modulator of N-methyl-d-aspartate (NMDA) receptors and a negative modulator of kainate and alphaamino-3-hydroxy-5-methyl-4-isoxazolepropionic acid (AMPA) receptors while pregnanolone sulfate (the most abundant conjugated pregnenolone isomer; Havlikova et al. 2006) exerts inhibitory effect on both NMDA and AMPA receptors (Sedlacek et al. 2008). Whereas the continued overstimulation of AMPA, kainate and NMDA receptors injures oligodendrocytes via the cytoplasmic calcium overload; the transitory one sensitizes these cells to complement attack as a consequence of oxidative stress (Matute 2011). Some authors suggest that pharmacological impairment of NMDA receptor signaling may be a part of a neuroprotection strategy in MS (Grasselli et al. 2013). Nevertheless, steroid polar conjugates like pregnenolone sulfate or pregnanolone sulfate most probably do not reach sufficient concentrations for efficient modulation of ionotropic receptors in the CNS (Hill et al. 2014). On the other hand, circulating allopregnanolone readily penetrates through the blood-brain barrier and at the same time fortifies the blood-brain barrier against the penetration of detrimental compounds from periphery (Kancheva et al. 2011, Melcangi et al. 2014, Noorbakhsh et al. 2014).

From the C19 steroids the levels of GABAergic androsterone and immunoprotective 5-androsten$3 \beta, 7 \alpha, 17 \beta$-triol were also higher in patients. The $7 \alpha$-hydroxy-androstanes like the latter steroid compete for the active sites on the enzyme catalyzing the conversion of inactive 11-oxo-glucocorticoids to immunosuppressive 11 $\beta$-hydroxy-glucocorticoids (Auci et al. 2009, Hennebert et al. 2007, 2008, Le Mee et al. 2008, Muller et al. 2006). In addition, the steroid $7 \alpha$-hydroxylating enzyme CYP7B1, converts the estrogen precursors such as androstenediol (also estrogenic) and DHEA to the $7 \alpha$-hydroxy-metabolites and thus hinders the formation of efficient estrogenic immunomodulators stimulating autoimmunity via estrogen receptors (Pettersson et al. 2008, 2010). More recent studies (Pettersson et al. 2010) show that there is no influence of DHEA to $7 \alpha$-hydroxy-DHEA conversion on the function of ER-mediated response as previously indicated, but the conversion of androstenediol to 5 -androstene $3 \beta, 7 \alpha, 17 \beta$ triol is effective.

In conclusion, our data demonstrate consistently higher levels of circulating C21 steroids and their polar conjugates and some bioactive C19 steroids in women with MS, which may influence neuronal activity and affect the balance between neuroprotection and excitotoxicity. However, further studies with a larger sample of participants are needed.

\section{Conflict of Interest}

There is no conflict of interest.

\section{Acknowledgements}

The study was supported by Grant NT/13814-4 of the Ministry of Health of the Czech Republic. 


\section{References}

AUCI DL, READING CL, FRINCKE JM: 7-Hydroxy androstene steroids and a novel synthetic analogue with reduced side effects as a potential agent to treat autoimmune diseases. Autoimmun Rev 8: 369-372, 2009.

BOVE R, CHITNIS T: The role of gender and sex hormones in determining the onset and outcome of multiple sclerosis. Mult Scler 20: 520-526, 2014.

CARUSO D, MELIS M, FENU G, GIATTI S, ROMANO S, GRIMOLDI M, CRIPPA D, MARROSU MG, CAVALETTI G, MELCANGI RC: Neuroactive steroid levels in plasma and cerebrospinal fluid of male multiple sclerosis patients. J Neurochem 130: 591-597, 2014.

DUSKOVA M, SIMUNKOVA K, HILL M, VELIKOVA M, KUBATOVA J, KANCHEVA L, KAZIHNITKOVA H, HRUSKOVICOVA H, POSPISILOVA H, RACZ B, SALATOVA M, CIRMANOVA V, KRALIKOVA E, STARKA L, PARIZEK A: Chronic cigarette smoking alters circulating sex hormones and neuroactive steroids in premenopausal women. Physiol Res 61: 97-111, 2012.

EL-ETR M, VUKUSIC S, GIGNOUX L, DURAND-DUBIEF F, ACHITI I, BAULIEU EE, CONFAVREUX C: Steroid hormones in multiple sclerosis. J Neurol Sci 233: 49-54, 2005.

EL-ETR M, GHOUMARI A, SITRUK-WARE R, SCHUMACHER M: Hormonal influences in multiple sclerosis: new therapeutic benefits for steroids. Maturitas 68: 47-51, 2011.

GRASSELli G, ROSSI S, MUSELlA A, GENTILE A, LOIZZO S, MUZIO L, Di SANZA C, ERRICO F, MUSUMECI G, HAJI N, FRESEGNA D, SEPMAN H, DE CHIARA V, FURLAN R, MARTINO G, USIELLO A, MANDOLESI G, CENTONZE D: Abnormal NMDA receptor function exacerbates experimental autoimmune encephalomyelitis. Br J Pharmacol 168: 502-517, 2013.

HAVLIKOVA H, HILL M, KANCHEVA L, VRBIKOVA J, POUZAR V, CERNY I, KANCHEVA R, STARKA L: Serum profiles of free and conjugated neuroactive pregnanolone isomers in nonpregnant women of fertile age. J Clin Endocrinol Metab 91: 3092-3099, 2006.

HENNEBERT O, CHALBOT S, ALRAN S, MORFIN R: Dehydroepiandrosterone 7alpha-hydroxylation in human tissues: possible interference with type 111 beta-hydroxysteroid dehydrogenase-mediated processes. $J$ Steroid Biochem Mol Biol 104: 326-333, 2007.

HENNEBERT O, PELISSIER MA, LE MEE S, WULFERT E, MORFIN R: Anti-inflammatory effects and changes in prostaglandin patterns induced by 7 beta-hydroxy-epiandrosterone in rats with colitis. J Steroid Biochem Mol Biol 110: 255-262, 2008.

HILL M, PARIZEK A, KANCHEVA R, DUSKOVA M, VELIKOVA M, KRIZ L, KLIMKOVA M, PASKOVA A, ZIZKA Z, MATUCHA P, MELOUN M, STARKA L: Steroid metabolome in plasma from the umbilical artery, umbilical vein, maternal cubital vein and in amniotic fluid in normal and preterm labor. $J$ Steroid Biochem Mol Biol. 121: 594-610, 2010.

HILL M, PASKOVA A, KANCEVA R, VELIKOVA M, KUBATOVA J, KANCHEVA L, ADAMCOVA K, MIKESOVA M, ZIZKA Z, KOUCKY M, SARAPATKOVA H, KACER V, MATUCHA P, MELOUN M, PARIZEK A: Steroid profiling in pregnancy: a focus on the human fetus. J Steroid Biochem Mol Biol 139: 201-222, 2014.

KANCHEVA R, HILL M, CIBULA D, VCELAKOVA H, KANCHEVA L, VRBIKOVA J, FAIT T, PARIZEK A, STARKA L: Relationships of circulating pregnanolone isomers and their polar conjugates to the status of sex, menstrual cycle, pregnancy. J Endocrinol 195: 67-78, 2007.

KANCHEVA R, HILL M, NOVAK Z, CHRASTINA J, KANCHEVA L, STARKA L: Neuroactive steroids in periphery and cerebrospinal fluid. Neuroscience 191: 22-27, 2011.

LE MEE S, HENNEBERT O, FERREC C, WULFERT E, MORFIN R: 7beta-hydroxy-epiandrosterone-mediated regulation of the prostaglandin synthesis pathway in human peripheral blood monocytes. Steroids 73: 1148$1159,2008$.

LEITNER H: Influence of neurosteroids on the pathogenesis of multiple sclerosis. Med Hypotheses 75: 229-234, 2010.

MADSEN R, LUNDSTEDT T, TRYGG J: Chemometrics in metabolomics - a review in human disease diagnosis. Anal Chim Acta 659: 23-33, 2010.

MATUTE C: Glutamate and ATP signalling in white matter pathology. J Anat 219: 53-64, 2011. 
MELCANGI RC, GIATTI S, CALABRESE D, PESARESI M, CERMENATI G, MITRO N, VIVIANI B, GARCIASEGURA LM, CARUSO D: Levels and actions of progesterone and its metabolites in the nervous system during physiological and pathological conditions. Prog Neurobiol 113: 56-69, 2014.

MELOUN M, HILL M, MILITKY J, KUPKA K: Transformation in the PC-aided biochemical data analysis. Clin Chem Lab Med 38: 553-559, 2000.

MELOUN M, MILITKY J, HILL M, BRERETON RG: Crucial problems in regression modelling and their solutions. Analyst 127: 433-450, 2002.

MELOUN M, HILL M, MILITKY J, VRBIKOVA J, STANICKA S, SKRHA J: New methodology of influential point detection in regression model building for the prediction of metabolic clearance rate of glucose. Clin Chem Lab Med 42: 311-322, 2004.

MULLER C, POMPON D, URBAN P, MORFIN R: Inter-conversion of 7alpha- and 7beta-hydroxydehydroepiandrosterone by the human 11 beta-hydroxysteroid dehydrogenase type 1. J Steroid Biochem Mol Biol 99: 215-222, 2006.

NOORBAKHSH F, ELLESTAD KK, MAINGAT F, WARREN KG, HAN MH, STEINMAN L, BAKER GB, POWER C: Impaired neurosteroid synthesis in multiple sclerosis. Brain 134: 2703-2721, 2011.

NOORBAKHSH F, BAKER GB, POWER C: Allopregnanolone and neuroinflammation: a focus on multiple sclerosis. Front Cell Neurosci 8: 134, 2014.

PETTERSSON H, HOLMBERG L, AXELSON M, NORLIN M: CYP7B1-mediated metabolism of dehydroepiandrosterone and 5alpha-androstane-3beta,17beta-diol--potential role(s) for estrogen signaling. FEBS J 275: 1778-1789, 2008.

PETTERSSON H, LUNDQVIST J, NORLIN M: Effects of CYP7B1-mediated catalysis on estrogen receptor activation. Biochim Biophys Acta 1801: 1090-1097, 2010.

SEDLACEK M, KORINEK M, PETROVIC M, CAIS O, ADAMUSOVA E, CHODOUNSKA H, VYKLICKY L JR: Neurosteroid modulation of ionotropic glutamate receptors and excitatory synaptic transmission. Physiol Res 57 (Suppl 3): S49-S57, 2008.

SPENCE RD, VOSKUHL RR: Neuroprotective effects of estrogens and androgens in CNS inflammation and neurodegeneration. Front Neuroendocrinol 33: 105-115, 2012.

TOMASSINI V, POZZILlI C: Sex hormones, brain damage and clinical course of Multiple Sclerosis. J Neurol Sci 286: 35-39, 2009.

TRYGG J, WOLD S: Orthogonal projections to latent structure. J Chemometrics 16: 119-128, 2002.

TRYGG J, HOLMES E, LUNDSTEDT T: Chemometrics in metabonomics. J Proteome Res 6: 469-479, 2007. 